\title{
Portfolio Optimization under Threshold Accepting: Further Evidence from a Frontier Market
}

\author{
Josephine M. Masese, Ferdinand Othieno, Carolyn Njenga \\ Institute of Mathematical Sciences, Strathmore University, Nairobi, Kenya \\ Email: josephine.masese@strathmore.edu,fothieno@strathmore.edu,cnjenga@strathmore.edu
}

How to cite this paper: Masese, J.M., Othieno, F. and Njenga, C. (2017) Portfolio Optimization under Threshold Accepting: Further Evidence from a Frontier Market. Journal of Mathematical Finance, 7, 941-957. https://doi.org/10.4236/jmf.2017.74052

Received: June 30, 2017

Accepted: November 25, 2017

Published: November 28, 2017

Copyright $\odot 2017$ by authors and Scientific Research Publishing Inc. This work is licensed under the Creative Commons Attribution International License (CC BY 4.0).

http://creativecommons.org/licenses/by/4.0/ (c) () Open Access

\begin{abstract}
Several improvements and alternatives to Mean Variance Optimization (MVO) have been suggested and used since its inception in 1952. The improvements have mostly included addition of constraints to the traditional MVO model, using alternative risk measures and using non risk-reward models. This paper seeks to compare MVO against the Threshold Accepting model, which is a general optimization model, in portfolio selection. Using data on 29 stocks in the Kenyan stock market we compare the relative performance of the two models using performance measures such as the Sharpe Ratio, Sortino Ratio and Information Ratio. We find that the Threshold Accepting (TA) model outperforms the Mean-Variance Optimization model though MVO yields similar results when we use monthly or weekly data but the latter is observed as a more consistent model. The TA model has portfolios with generally more superior risk-adjusted returns for the full period and during periods of high volatility in the stock market performance market. This observation implies that relatively more attention should be given to the TA model rather than relying entirely on the classical MVO approach.
\end{abstract}

\section{Keywords}

Mean-Variance Optimization, Threshold Accepting, Frontier Market

\section{Introduction}

Traditionally, mean-variance analysis as proposed by [1] [2] has been used in portfolio optimization where risk and return are traded off. Mean-variance analysis gives a theory of investor behavior regardless of whether the market as a whole is in equilibrium. Under MVO, every reasonable investor would want a 
portfolio where the return is maximized and the risk is minimized; that is, for a given level of risk, an investor would choose the portfolio with the maximum return.

Several other authors have argued that mean-variance analysis may not be applicable in some cases, for example, when return distributions are too spread out [3]. Consequently, alternative ways to portfolio construction are suggested, three of which stand out. Firstly, the use of other measures of risk or return in a risk-return analysis, secondly, determining the investor's utility function explicitly and maximizing its expected value and thirdly, use of constraints and guidelines to select preferred portfolio instead of risk-return optimization.

Alternative risk measures to the variance and use of techniques that do not require the mean or variance of returns by utilizing objective functions have since been introduced to offer better optimization results. The semi-variance, mean absolute deviation (MAD), Minimax, Maximum Loss, Value-at-Risk (VaR), Conditional Value-at-Risk (CVaR) and partial moments are some of the main alternative risk measures that have been used. Further to these, models that are non risk-reward but are based on simulations incorporating set requirements have been researched on; most of these do not rely on the returns distribution. Recently, [4] propose a semivariance method for diversified portfolio selection, in which the security returns are given by subjective expert estimations and depicted as uncertain variables. Due to the difficulty involved in solving the models, the authors employ a hybrid intelligent algorithm which is based on 99-method and genetic algorithm to solve the models. See [5] for further details on portfolio selection in uncertain environments in which security returns cannot be well reflected by historical data, but can be evaluated by the experts.

Linear simulations and other algorithms have been used for portfolio selection with the most common ones including, Threshold Accepting (TA) [6]; and, the Genetic Algorithm (GA) used together with a risk measure [7]. These are non risk-reward heuristic models ${ }^{1}$; where risk and reward as measures of portfolio performance are not dismissed but are incorporated as part of the specifications. As opined by [10], heuristic models outperform many optimisation models which are difficult to solve because they have multiple local optima or are "badly-behaved" in other ways. Such models can be handled by heuristics such as Threshold Accepting.

In the Kenyan market, Portfolio managers mainly use the mean-variance analysis and factor models in portfolio selection. These traditional models are viewed as useful and acceptable since they have been applied frequently for a long time. Sometimes, excessive caution is taken in using newer techniques due to the uncertainty involved. Despite its widespread application, the MVO suffers from serious limitations, key of which is its disregard for the overall shape of the distribution of the returns and, its sole concern about the final wealth and not the path the wealth

${ }^{1}$ A heuristic optimization model is a general purpose optimization method which searches for a solution in a systematic programmed way. See details in [8] and [9]. 
takes between from initiation of the investment (See [8] and [9]). In addition, there is sufficient evidence regarding the underperformance of the MVO model to other models, even the single index model (See [11]) for details).

Based on 29 stocks in the Kenyan stock market this paper uses the Threshold Accepting model in constructing optimal portfolios and compares risk-adjusted performance across the portfolios selected with by the MVO model to determine the most optimal model best model for optimization. Varying time periods are also considered to check the consistency of the performance of the TA versus the MVO model. The paper presents a novel empirical stance using data from a frontier market that would otherwise be left out of most empirical work.

The Threshold Accepting (TA) model was introduced by [6] as a general purpose optimization algorithm. TA has since then been severally applied to optimization problems and compared to other optimization models. It looks for solutions by optimizing the set objective function through reiterations that improve the solution at each subsequent iteration hence meeting any set constraints [8]. TA has been recommended as an optimization model that leads to better optimization results over classical optimization approaches [12].

\section{Mean-Variance Optimization}

The mean-variance analysis framework of [1] hypothesizes portfolio selection as a function of portfolio returns mean and variance. Variance (or its root: standard deviation) is used as a measure of risk in this model and MVO was fronted to have portfolio selection based on reasonable beliefs about future rather than past performance only where variability of return in the past is a good measure of the uncertainty of return in the future.

MVO being a solution to a resource allocation problem, the investor needs to choose a portfolio of $n$ risky assets with weights $\left[w_{1}, w_{2}, \cdots, w_{n}\right]$ that would minimize the risk (variance) at a given level of return. The objective of MVO in portfolio selection is:

$$
\begin{array}{cc}
\text { Min } \sigma_{p}^{2}=w^{\prime} \Sigma w \\
\text { s.t. } & w^{\prime} R \geq \bar{R} \\
& w^{\prime} \mathbf{1}=1 \\
& w_{i} \geq 0
\end{array}
$$

where $\bar{R}$ is the minimal rate of return required by an investor and $\Sigma$ is the covariance matrix. The Treasury Bill effective rate is used as a proxy for the risk-free rate which is set as the minimal rate of return required by an investor.

\subsection{Improvements to Mean-Variance Optimization}

The inclusion of constraints in the MVO problem can lead to better out-of-sample performance when compared to portfolios constructed without constraints. In practice, most portfolio optimization problems have a number of constraints including regulatory (reflect restrictions imposed by market 
regulators), guideline (limits or conditions specified by client), exposure constraints made at the discretion of the portfolio manager, trading constraints (discretionary limits on positions or trades), risk management constraints and transfer coefficients [9]. However, constraints and guidelines have to be imposed carefully since they may distort robustness and stability of the portfolio allocation. Judgment and constraints should be incorporated cautiously to have the estimates of return and risk as more forward looking rather than historical [7].

A different approach, the Black-Litterman Model, is proposed by [13]. This approach uses a Bayesian approach by combining investors' views regarding performance of stocks in a way that allows intuitive diversified portfolios. Investors' views, being subjective, are modelled together with the market equilibrium of expected returns. In addition, confidence intervals on the views are specified for incorporation in adjustments for final portfolio weights. When an investor does not have any view about a stock, he is taken to hold the market equilibrium. Views on a few assets imply changes to the expected returns on all assets due to correlation of securities. This ensures that the portfolio composition is diverse and not in just a few assets. Having obtained these inputs, the MVO technique is run.

\subsection{Alternatives to Mean-Variance Optimization}

One of the alternatives to MVO is determining an investor's utility function and maximizing it. However, there is great difficulty in finding an appropriate utility function to use due to changing perception of the investor [7].

The use of alternative measures of risk or return in a risk-return analysis is another way of constructing better optimized portfolios and in overcoming the shortcomings of mean-variance analysis [8] [9] [14]-[16]. The VaR, CVaR, semi-variance, MAD, Minimax, Maximum Loss and partial moments are some of the alternative risk measures used together with the mean in portfolio optimization.

It is worthwhile to note that some risk measures give the same result in portfolio selection when the portfolio distributions depend only on the first two moments; but, if the returns distributions is skewed, the risk measures perform differently [17]. Furthermore, risk-averse investors prefer mean-variance in optimal asset allocation while less risk-averse ones prefer where the mean is combined with an alternative risk measure.

Other ways of diversifying the risks and returns in a portfolio were suggested by [18]. These include, allocation of weights equally across selected securities which will not be subject to estimation errors. Secondly, using the risk-parity approach where the total portfolio risk is shared equally across the investment securities (risk parity approach), and; thirdly, using a risk model without a return model, for example measuring risk using the variance of the portfolio return as in the global minimum variance portfolio. The technique of risk 
allocation across different risk factors in an equity portfolio as a risk management constraint was fronted.

Authors such as [19] found that construction of efficient portfolios is better done by using risk factors rather than using mean-variance analysis. This technique takes the fundamental factor model approach where risk factors that explain company attributes were determined and used as indices.

Lately, heuristic models which act as general optimization models are increasingly being applied in portfolio optimization problems [20] because of their ability to take into account different characteristics of return distributions. This paper uses one such model, the Threshold Accepting model, for optimization and compares its performance against the MVO model for optimal portfolio selection.

\section{Threshold Accepting (TA)}

Threshold Accepting uses a set of rules incorporating objective functions and includes risk and reward measures as constraints in portfolio selection. Several asset combination scenarios for a portfolio are considered and the most optimal one is chosen with checks put in place to minimize uncertainty of the model hence making it robust.

This model involves creating different scenarios and comparing the portfolios formed to select the optimal portfolio. TA works by always accepting a solution that improves the objective function and only accepts a deterioration only if it is not worse than the set threshold [6].

The first solution of TA is a random solution that meets the objective function and thresholds set and from this initial solution improvements are "created" until the best solution is found; this solution is then chosen as the optimum [9] and $[6]$.

The objective of the model is:

$$
\begin{array}{ll}
\operatorname{Min}_{w} & \phi(r) \\
\text { s.t. } & w_{j}^{\text {inf }} \leq w_{j} \geq w_{j}^{\text {sup }}, j \in P, \\
& n_{\text {inf }} \leq n_{\text {sup }}
\end{array}
$$

where $w_{j}^{\text {inf }}$ and $w_{j}^{\text {sup }}$ are minimum and maximum weights for the stock in the portfolio; $P$ is the set of individual stocks in the portfolio; and, $n_{\text {inf }}$ and $n_{\text {sup }}$ are constraints setting the minimum and maximum number of stocks in the portfolio, $\mathrm{P}[6]$ [9].

The implementation of the TA model/algorithm requires the definition of the objective function $f$, the neighbourhood $N\left(x^{c}\right)$-where $x^{c}$ is the current best solution- and the threshold sequence $\tau$ which gradually reduces to zero in a given number of rounds [6]. The neighbourhood is defined as the subsequent portfolios that offer a better return at a given minimum risk or portfolios that have a lower risk at a given return as compared to the portfolios already formed.

In their analysis, [9] propose the following Threshhold accepting pseudo code: 


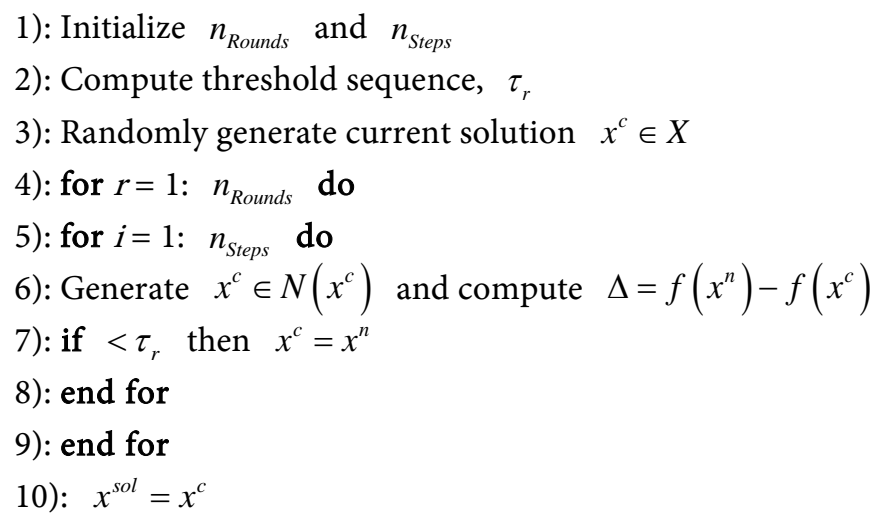

where $f$ is the objective function, $X$ is the set of feasible solutions, $x^{c}$ is the current solution, $x^{n}$ is an alternative solution close to $x^{c}$.

In this paper, the thresholds that are applied are capping the weights for stock in the portfolio at $30 \%$, restricting the number of stock in the portfolio to between 3 and 10 stocks and setting the minimum return acceptable as the Nairobi All Share Index (NASI) return.

These thresholds represent bounds/expectations of an investor in the Kenyan stock market. An investor typically would not want to invest in many stocks at a go but would also wish to diversify their portfolio to select a small number of stocks.

The NASI return is used as the benchmark for the minimum acceptable return since one would wish to invest in stocks which at least perform in the same way as the market index.

All algorithms employed in this paper are implemented using Solver and VBA for MS Excel. The MVO optimization scheme takes approximately three minutes for monthly returns and six minutes for weekly returns. Threshold Accepting took approximately six minutes for monthly returns and twelve minutes for weekly returns.

\section{Main Results}

In this section, the portfolios selected by the two models considered is shown together with the performance ratios which are used to determine the better performing model. The research uses weekly and monthly data of 29 stocks spanning 19 years between 1998 and 2016 from the Nairobi Securities Exchange (NSE) [21].

The stocks selected by the MVO model for the full period (1998-2016) are shown in the following tables for the weekly and monthly stock returns data: where $i$ represents a stock, $w_{i}$ is the weight of the stock in the portfolio, $\bar{R}_{P}$ is the portfolio return and $\sigma_{P}$ is the portfolio standard deviation.

Based on the weekly analysis, we can see in Table 1 below, that BOC, EABL, $\mathrm{BAMB}$, and $\mathrm{C} \& \mathrm{G}$ take the largest allocations respectively. BOC and EABL are in the Manufacturing sector, BAMB is in the Construction sector while $C \& G$ is in the Automobiles sector. BOC is selected for its low risk while the other stocks 
Table 1. Stock composition and return \& risk of optimal portfolio selected by the MVO model on weekly stock returns data 1998-2016.

\begin{tabular}{cccc}
\hline$i$ & $w_{i}$ & $\bar{R}_{p}$ & $\sigma_{p}$ \\
\hline STOCK & WEIGHTS & Portfolio Return & Portfolio Std Dev \\
\hline BAMB & $10.2217 \%$ & $2.7165 \%$ & \\
BBK & $3.6704 \%$ & & \\
BERG & $1.6732 \%$ & \\
BOC & $25.5548 \%$ & \\
C\&G & $5.9519 \%$ & \\
CFC & $2.7401 \%$ & \\
DTK & $3.1351 \%$ & \\
EABL & $10.3260 \%$ & \\
JUB & $2.5483 \%$ & \\
KENO & $2.7209 \%$ & \\
KQ & $0.6804 \%$ & \\
KUKZ & $4.9227 \%$ & \\
NMG & $1.3584 \%$ & \\
OCH & $1.2744 \%$ & \\
SASN & $0.6090 \%$ & \\
SCBK & $5.7813 \%$ & \\
SGL & $0.4096 \%$ & \\
SNLM & $4.9117 \%$ & \\
TOTL & $5.5638 \%$ & \\
UNGA & $0.1421 \%$ & \\
XPRS & $5.8044 \%$ & \\
\hline
\end{tabular}

The portfolio majorly consists of four stocks (BOC, EABL, BAMB, and C\&G) which belong to three different industry sectors-Manufacturing, Construction and Automobiles sector.

selected have high returns with relatively low risks.

The monthly optimized portfolio comprises the same stocks but also includes SCBK (Banking Sector) among its largest allocations (Table 2). This shows that this model yields similar resultsis consistent regardless of the time period considered.

Despite the monthly portfolio having more stock hence being more diversified, it has lower expected returns with higher variance as compared to the weekly portfolio. The optimization results for the Threshold Accepting model are as shown in Table 3 and Table 4.

Only four stocks are selected in the weekly analysis for the TA portfolio; these can be seen in Table 3 below-EABL (Manufacturing sector), JUB (Insurance sector), KENO (Energy sector) and ICDC (Investment sector). All the stocks selected are in different industry sectors.

In the monthly TA portfolio, we have the largest allocation to EABL, KENO, JUB, ARM (Manufacturing sector) and DTK (Banking sector) stocks (Table 4). 
Table 2. Stock composition and return \& risk of optimal portfolio selected by the MVO model on monthly stock returns data 1998-2016.

\begin{tabular}{cccc}
\hline$i$ & $w_{i}$ & $\bar{R}_{p}$ & $\sigma_{p}$ \\
\hline STOCK & WEIGHTS & Portfolio Return & Portfolio Std Dev \\
\hline BAMB & $7.0698 \%$ & $2.2270 \%$ & $1.848 \%$ \\
BOC & $30.5265 \%$ & & \\
C\&G & $9.9547 \%$ & & \\
CFC & $1.3551 \%$ & & \\
EABL & $14.875 \%$ & \\
KENO & $1.7713 \%$ & \\
KQ & $4.4192 \%$ & & \\
KUKZ & $3.6636 \%$ & & \\
NMG & $0.7691 \%$ & & \\
OCH & $1.0371 \%$ & \\
SASN & $2.7608 \%$ & \\
SCBK & $10.4343 \%$ & \\
SGL & $0.2527 \%$ & \\
SNLM & $2.4087 \%$ & \\
\hline
\end{tabular}

The greatest weights are given to BOC (Manufacturing), EABL (Manufacturing), SCBK (Banking), C\&G (Automobiles) and BAMB (Construction); these selected stocks are in different sectors except for the first two.

Table 3. Stock composition and return \& risk of optimal portfolio selected by the TA model on weekly stock returns data 1998-2016.

\begin{tabular}{cccc}
\hline$i$ & $w_{i}$ & $\bar{R}_{p}$ & $\sigma_{P}$ \\
\hline STOCK & WEIGHTS & Portfolio Return & Portfolio Std Dev \\
\hline EABL & $30.0000 \%$ & $7.9377 \%$ & $1.3824 \%$ \\
ICDC & $10.0000 \%$ & & \\
JUB & $30.0000 \%$ & & \\
KENO & $30.0000 \%$ & & \\
\hline
\end{tabular}

The portfolio selects EABL (Manufacturing), ICDC (Investment), JUB (Insurance) and KENO (Energy). All stocks selected are in different sectors with the maximum weight in the TA threshold, (30\%), allocated to three stocks. The selected stocks are a subset of stocks selected by the monthly TA portfolio in Table 4.

Most of these stocks are also in different sectors for the respective models' portfolios. The weekly TA portfolio is a subset of the monthly TA portfolio.

The portfolios formed by the two optimization models considered, have been tested and ranked using the three performance ratios: Sharpe ratio, information ratio and Sortino ratio as shown in Table 5.

Most of the ratios obtained are negative since the average stock returns are less than the risk free rate for the period considered.

The Sharpe ratios are negative numbers indicating that holding the risk free security is superior to holding stock portfolios. The TA portfolio offers a better performance when compared to the MVO portfolio since it has higher Sharpe 
Table 4. Stock composition and return \& risk of optimal portfolio selected by the TA model on monthly stock returns data 1998-2016.

\begin{tabular}{cccc}
\hline$i$ & $w_{i}$ & $\bar{R}_{p}$ & $\sigma_{p}$ \\
\hline STOCK & WEIGHTS & Portfolio Return & Portfolio Std Dev \\
\hline ARM & $11.717 \%$ & $5.4409 \%$ & $2.5819 \%$ \\
BOC & $4.5711 \%$ & & \\
CG & $3.2149 \%$ & & \\
DTK & $10.0202 \%$ & & \\
EABL & $28.3888 \%$ & \\
HFCK & $2.1922 \%$ & \\
ICDC & $1.786 \%$ & \\
JUB & $12.9509 \%$ & \\
KENO & $17.1471 \%$ & \\
OCH & $6.3906 \%$ & \\
\hline
\end{tabular}

The greatest weights are given to EABL (Manufacturing), KENO (Energy), JUB (Insurance), ARM (Manufacturing) and DTK (Banking). Portfolio return is less than the weekly TA portfolio in Table 3 and also has higher risk.

Table 5. Performance Ratios of portfolios (weekly and monthly) selected by the MVO and TA models.

\begin{tabular}{cccccc}
\hline & & \multicolumn{3}{c}{ Performance Ratios } \\
\cline { 2 - 6 } & $\bar{R}_{p}$ & $\sigma_{P}$ & Sharpe ratio & IR & Sortino Ratio \\
\hline MVO Portfolio - weekly & $2.7165 \%$ & $0.8116 \%$ & $-8.8401 \%$ & $-0.0182 \%$ & $-0.2749 \%$ \\
TA Portfolio - weekly & $7.9397 \%$ & $1.3824 \%$ & $-1.4118 \%$ & $0.2983 \%$ & $-0.0696 \%$ \\
MVO Portfolio - monthly & $2.227 \%$ & $1.8482 \%$ & $-4.1149 \%$ & $-0.6865 \%$ & $-0.7738 \%$ \\
TA Portfolio - monthly & $5.4409 \%$ & $2.5819 \%$ & $-1.7007 \%$ & $0.7684 \%$ & $-0.4507 \%$ \\
\hline
\end{tabular}

A summary of the returns, standard deviation \& performance ratios values of the portfolios selected by the MVO and TA models for the full period 1998-2016. Performance ratios of the TA portfolios are higher than those for the MVO portfolios, with the TA portfolios exhibiting higher risk and returns.

ratios in comparison.

In order to obtain the IR and Sortino ratios, portfolios of the stocks are formed over each data point using the weights shown in Tables 1-4. The IR gives positive values for the TA portfolios unlike the MVO portfolios, showing that the TA model portfolio outperformed the benchmark index. The Sortino ratios are negative ratios for both models but the TA model is still potrayed as superior since it has higher values.

We however note that the TA portfolios carry a higher risk as compared to the MVO portfolios. This is due to the risk return trade-off.

Figure 1 and Figure 2 give a summary of returns of portfolios formed by the two optimization models used in this paper for the full-period analysis.

The period 1998 to 2016 is divided into four periods (1998-2002, 2003-2007, 2008-2012, 2013-2016) to test consistency in performance of the MVO and TA optimization models using the weekly stock returns data. The four sub-periods 


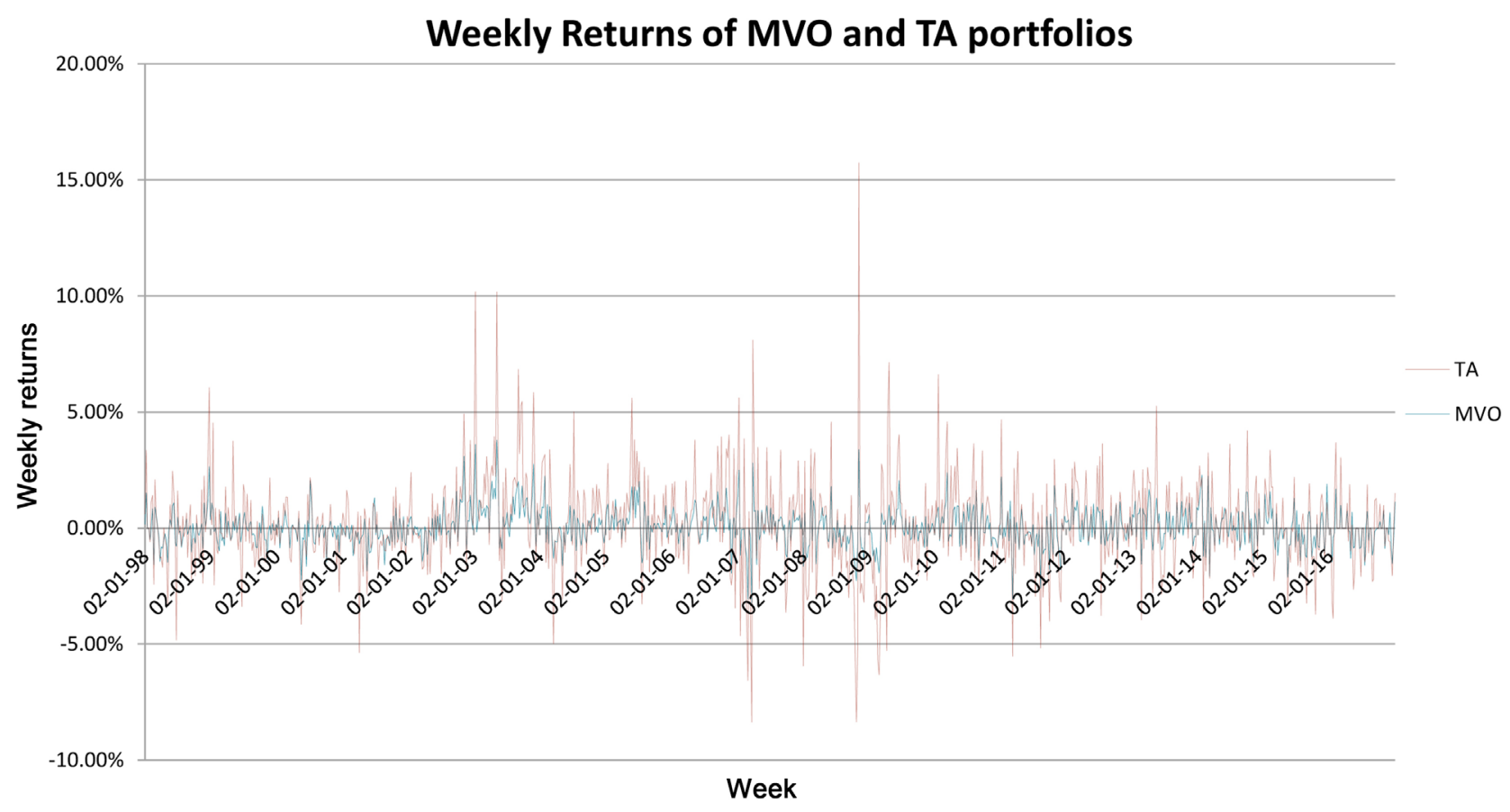

Figure 1. Portfolio returns of portfolios selected by MVO \& TA models in the weekly stock returns data 1998-2016.

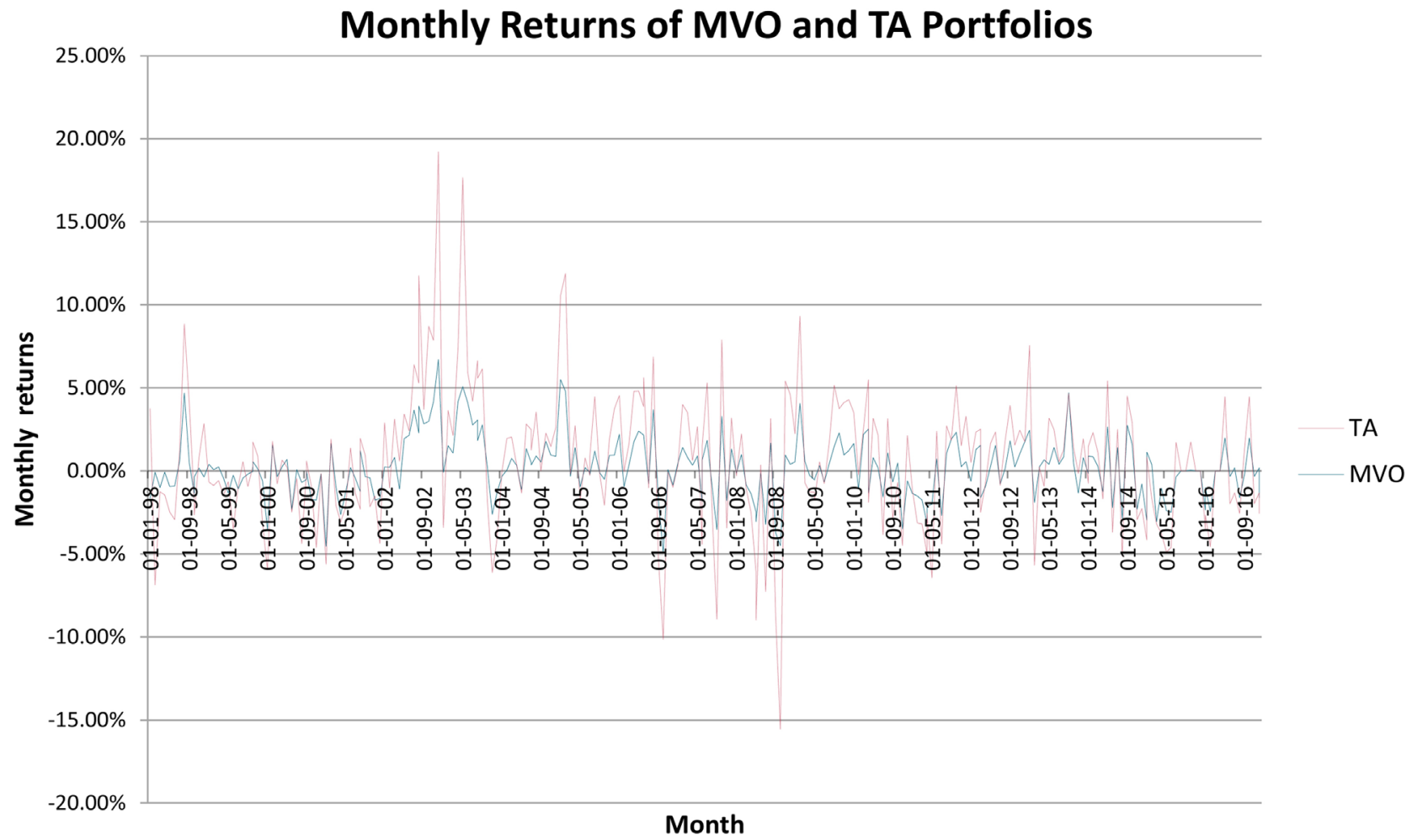

Figure 2. Portfolio Returns of portfolios selected by MVO \& TA models in the monthly stock returns data 1998-2016.

are selected based on Kenya's election cycle. This is because research has shown that the stock market performance is affected by the uncertainty during election periods where there are abnormal returns (negative and positive) in the periods 
immediately preceeding and superceeding the elections [15] [22] and stock prices become less informative [23].

The portfolios selected for the sub-periods are shown in Tables 6-8.

Table 6. Stock composition of portfolios selected by the MVO and TA models in the period 1998-2002.

\begin{tabular}{|c|c|c|c|c|c|c|c|}
\hline \multicolumn{8}{|c|}{ Portfolio composition for $1998-2002$} \\
\hline & MVO & & & & TA & & \\
\hline & model & & & & Model & & \\
\hline$i$ & $w_{i}$ & $\bar{R}_{p}$ & $\sigma_{P}$ & $i$ & $w_{i}$ & $\bar{R}_{p}$ & $\sigma_{P}$ \\
\hline BAMB & $11.2778 \%$ & $0.00000007 \%$ & $0.8531 \%$ & BOC & $29.97 \%$ & $0.034993 \%$ & $1.0833 \%$ \\
\hline BBK & $3.4963 \%$ & & & EABL & $29.63 \%$ & & \\
\hline BERG & $2.7179 \%$ & & & SCBK & $9.93 \%$ & & \\
\hline BOC & $23.9029 \%$ & & & TOTL & $29.63 \%$ & & \\
\hline $\mathrm{C} \& \mathrm{G}$ & $5.8803 \%$ & & & & & & \\
\hline $\mathrm{CFC}$ & $1.8022 \%$ & & & & & & \\
\hline EABL & $18.3178 \%$ & & & & & & \\
\hline JUB & $1.5118 \%$ & & & & & & \\
\hline KENO & $6.0926 \%$ & & & & & & \\
\hline NMG & $2.879 \%$ & & & & & & \\
\hline SCBK & $10.3863 \%$ & & & & & & \\
\hline SNLM & $3.7827 \%$ & & & & & & \\
\hline TOTL & $5.0586 \%$ & & & & & & \\
\hline
\end{tabular}

The greatest weights are given to similar stocks by both models' portfolios. The MVO portfolio has BOC (Manufacturing), EABL (Manufacturing), BAMB (Construction) and SCBK (Banking) while the TA portfolio has BOC, EABL, SCBK and TOTL (Energy). This period had poor stock performance with the MVO portfolio return being very low.

Table 7. Stock composition of portfolios selected by the MVO and TA models in the period 2003 to 2007.

\begin{tabular}{|c|c|c|c|c|c|c|c|}
\hline \multicolumn{8}{|c|}{ Portfolio composition for $2003-2007$} \\
\hline & $\begin{array}{l}\text { MVO } \\
\text { model }\end{array}$ & & & & TA Model & & \\
\hline$i$ & $w_{i}$ & $\bar{R}_{p}$ & $\sigma_{p}$ & $i$ & $w_{i}$ & $\bar{R}_{p}$ & $\sigma_{P}$ \\
\hline ARM & $11.9324 \%$ & $6.5 \%$ & $1.5635 \%$ & ARM & $27.6421 \%$ & $6 \%$ & $1.47 \%$ \\
\hline CABL & $36.6295 \%$ & & & BAMB & $0.951 \%$ & & \\
\hline $\mathrm{CFC}$ & $8.1925 \%$ & & & CABL & $11.9844 \%$ & & \\
\hline DTK & $8.1195 \%$ & & & $\mathrm{CFC}$ & $17.1365 \%$ & & \\
\hline JUB & $16.5975 \%$ & & & DTK & $2.0104 \%$ & & \\
\hline $\mathrm{KCB}$ & $6.447 \%$ & & & EABL & $2.246 \%$ & & \\
\hline KENO & $1.5244 \%$ & & & JUB & $25.1877 \%$ & & \\
\hline \multirow[t]{3}{*}{ SNLM } & $10.5456 \%$ & & & КCB & $4.9982 \%$ & & \\
\hline & & & & KENO & $0.5088 \%$ & & \\
\hline & & & & SNLM & $6.3375 \%$ & & \\
\hline
\end{tabular}

The greatest weights are also given to similar stocks by both models' portfolios as is the case in Period One (Table 6). The MVO portfolio has CABL (Construction), JUB (Insurance), ARM (Construction) and SNLM (Insurance) while the TA portfolio has ARM, JUB, CABL and CFC (Banking). This period had superior stock performance with the MVO portfolio having higher performance ratios than the TA portfolio. 
Table 8. Stock composition of portfolios selected by the MVO and TA models in the period 2008 to 2012 .

\begin{tabular}{cccccccc}
\hline \multicolumn{7}{c}{ Portfolio composition for 2008-2012 } \\
\hline \multicolumn{1}{c}{$\begin{array}{c}\text { MVO } \\
\text { model }\end{array}$} & \multicolumn{7}{c}{$\begin{array}{c}\text { TA } \\
\text { Model }\end{array}$} \\
\hline$i$ & $w_{i}$ & $\bar{R}_{p}$ & $\sigma_{p}$ & $i$ & $w_{i}$ & $\bar{R}_{p}$ & $\sigma_{p}$ \\
\hline ARM & $24.9392 \%$ & $1.2 \%$ & $1.3607 \%$ & ARM & $28.5528 \%$ & $1.2 \%$ & $1.4384 \%$ \\
DTK & $12.2033 \%$ & & & DTK & $10.0118 \%$ & & \\
EABL & $32.5624 \%$ & & & EABL & $29.9954 \%$ & & \\
KUKZ & $24.7311 \%$ & & & KQ & $1.0864 \%$ & & \\
NMG & $5.5639 \%$ & & & KUKZ & $29.9944 \%$ & & \\
\hline
\end{tabular}

Highest portfolio weights are allocated to similar stocks by both the MVO and TA models. The MVO portfolio selects EABL (Manufacturing), ARM (Construction), KUKZ (Agricultural), DTK (Banking) and NMG (Commercial) while the TA portfolio is a sub-set of the MVO portfolio comprising EABL, ARM, KUKZ and DTK.

For the period 1998-2002, the MVO model consists of various stocks with the largest allocations in BOC (Manufacturing sector), EABL (Manufacturing sector), BAMB (Construction sector) and SCBK (Banking sector) consisting of three industry sectors as is shown in Appendix; while the TA model portfolio consists of four stocks, BOC (Manufacturing sector), EABL (Manufacturing sector), SCBK (Banking sector) and TOTL (Energy sector) which are companies in three different sectors also. The two portfolios have a similar composition with only one different stock among the ones selected in each.

The TA model outperforms the MVO model in this period since all its performance ratios are higher than the MVO model as is shown in Table 10. The TA model portfolio has higher returns but at a higher risk as compared to the MVO model.

The performance of the stock market during this period was poor. This can be seen in Table 10 where the portfolios performance ratios for this period are high negative values.

For the period 2003-2007, the highest allocations for the MVO model portfolio are in CABL (Construction sector), JUB (Insurance sector), ARM (Construction sector) and SNLM (Insurance sector); while the TA model portfolio has ARM (Construction sector), JUB (Insurance sector), CFC (Banking sector) and CABL (Construction sector) with the highest allocations.

Based on the risk-adjusted performance ratios, the MVO model outperforms the TA model in this period (Table 10). The performance ratios are also positive indicating that the stock market was performing well.

For the period 2008-2012, the MVO model portfolio consists of the following stocks: EABL (Manufacturing sector), ARM (Construction sector), KUKZ (Agricultural sector), DTK (Banking sector) and NMG (Commercial sector). The highest allocations in the TA portfolio model are a sub-set of the MVO model stocks with NMG excluded. See Table 9 below for the period 2013-2016. 
Table 9. Stock composition of portfolios selected by the MVO and TA models in the period 2013 to 2016.

\begin{tabular}{|c|c|c|c|c|c|c|c|}
\hline \multicolumn{8}{|c|}{ Portfolio composition for 2013-2016 } \\
\hline & MVO & & & & TA & & \\
\hline & model & & & & Model & & \\
\hline$i$ & $w_{i}$ & $\bar{R}_{p}$ & $\sigma_{P}$ & $i$ & $w_{i}$ & $\bar{R}_{p}$ & $\sigma_{p}$ \\
\hline CFC & $2.072 \%$ & $3.8 \%$ & $1.6271 \%$ & $\mathrm{CFC}$ & $6.9636 \%$ & $3.5 \%$ & $1.52 \%$ \\
\hline ICDC & $19.0275 \%$ & & & ICDC & $27.1942 \%$ & & \\
\hline JUB & $26.1958 \%$ & & & JUB & $29.9951 \%$ & & \\
\hline KUKZ & $47.7456 \%$ & & & KUKZ & $29.9994 \%$ & & \\
\hline UNGA & $4.955 \%$ & & & UNGA & $5.7775 \%$ & & \\
\hline
\end{tabular}

The greatest weights are given to the same stocks by both models' portfolios: KUKZ (Agricultural), JUB (Insurance) and ICDC (Investment) but at different proportions. The MVO model has higher performance ratios.

Table 10. Performance ratios values of MVO \& TA model portfolios for the four sub-periods: 1998-2002, 2003-2007, 2008-2012 and 2013-2016.

\begin{tabular}{cccccc}
\hline & \multicolumn{5}{c}{ Performance measure values } \\
\cline { 2 - 6 } & $\bar{R}_{p}$ & $\sigma_{P}$ & Sharpe ratio & IR & $\begin{array}{c}\text { Sortino } \\
\text { Ratio }\end{array}$ \\
\hline MVO Portfolio-1998-2002 & $0.00000007 \%$ & $0.8531 \%$ & $-18.1128 \%$ & $-20.4355 \%$ & $-10.954 \%$ \\
TA Portfolio-1998-2002 & $0.035 \%$ & $1.0833 \%$ & $-14.2313 \%$ & $-13.5473 \%$ & $-9.6618 \%$ \\
(1)2-6 MVO Portfolio-2003-2007 & $6.5 \%$ & $1.5635 \%$ & $0.3378 \%$ & $0.2496 \%$ & $0.0906 \%$ \\
TA Portfolio-2003-2007 & $6 \%$ & $1.4744 \%$ & $0.0191 \%$ & $0.0144 \%$ & $0.0048 \%$ \\
(1)2-6 MVO Portfolio-2008-2012 & $1.2 \%$ & $1.3607 \%$ & $-5.337 \%$ & $-1.9485 \%$ & $-0.8575 \%$ \\
TA Portfolio-2008-2012 & $1.2 \%$ & $1.4384 \%$ & $-5.0487 \%$ & $-1.7117 \%$ & $-0.8387 \%$ \\
(1)2-6 MVO Portfolio-2013-2016 & $3.8 \%$ & $1.6271 \%$ & $-3.7446 \%$ & $0.0295 \%$ & $-0.6282 \%$ \\
TA Portfolio-2013-2016 & $3.5 \%$ & $1.5177 \%$ & $-4.2121 \%$ & $-0.1564 \%$ & $-0.6283 \%$ \\
\hline
\end{tabular}

These performance ratios are used to rank the MVO and TA models by their portfolios shown in Table 10 for the sub-period analysis. The MVO model performs better in the periods 2003-2007 and 2013-2016 where its portfolios have higher performance ratios, while the TA model performs better in the other two sub-periods.

The MVO model outperforms the TA model in this period as can be seen by the performance ratios in Table 10 .

As can be seen in Table 9 above, the MVO model portfolio for the sub-period 2013-2016 has KUKZ (Agricultural sector), JUB (Insurance sector) and ICDC (Investment sector) stocks with the highest allocations while the TA model portfolio comprises the same stocks but also has CFC (Banking sector) and UNGA (Manufacturing sector) with sizeable allocations.

The MVO model outperforms the TA model in this period as can be seen from the performance ratios in Table 10.

\subsection{Full Sampleperiod Analysis Summary}

For the full period analysis, optimization over the weekly periods yields better 
portfolios, in terms of higher returns and lower risk, as compared to the monthly period.

The two optimization models mainly selected stocks from different sectors implying that optimal stock portfolios are well diversified by considering stocks of companies in different industries. This is as shown in Tables 1-4. This finding agree with the conclusion of [22], that diversification across sectors leads to better portfolio performance. Consistent with the work of [22], we also carry out analysis on a weekly basis which signal more timely information as compared to the monthly analysis.

The MVO model has a similar set of stock in the weekly and monthly return portfolios indicating that it is a consistent model, in the sense that the portfolio selection does not vary with the horizon selected, whether weekly or monthly. In the TA model, the monthly portfolio considers more stocks than the weekly portfolio which seems to have naively selected high return stocks.

\subsection{Sub-Sample Analysis Summary}

The performance ratios of portfolios selected by the two models for the subperiods is as shown in Table 10 .

The MVO model outperforms the TA model in two out of the four subperiods as can be seen by the ratio values in Table 10 above. These periods (2003-2007 \& 2013-2016) also exhibit better stock market performance than the other two subperiods.

The stocks comprising the portfolios formed are also majorly from different sectors, hence the portfolios are diversified. Over the different sub-periods we mainly have stocks from the Construction, Manufacturing, Insurance and Banking sectors selected.

\section{Conclusions and Recommendations}

This paper concludes that the TA model outperforms the MVO model for portfolio selection but it does not perform well consistently over different time periods. This is in line with what [12] found, that heuristic models lead to overall superior results over the MVO approach; however, [12] further concludes that portfolio compositions from heuristic approaches are more stable. [3] also concludes that employing techniques that lead to running optimization over created scenarios and different risk measures other than variance, offers an improvement to the traditional mean-variance optimization models.

The TA model portfolios have higher returns than MVO model but at a higher risk cost. This would be appealing for investors who are risk takers. [13] has the same conclusion on the single index model in comparison with the MVO model.

Investors in the Kenyan stock market, especially fund managers who act on behalf of their clients can explore the benefits of using the TA model in making decisions on stock investment holdings. 
Adding to the voice of [11] who recommend use of new approaches to portfolio construction including the single index model and use of new risk measures which takes investors' views into account as in [13]; we opine that alternative models prove fruitful for the Kenyan stock market since it will enable use of better constraints and thresholds for the MVO and TA models respectively. Future research could extend the analysis to other frontier markets in Africa and compare the results with emerging markets such as South Africa.

\section{Acknowledgements}

Sincere thanks to the participants of the Fifth Strathmore International Mathematics Conference for their invaluable guidance and help concerning this research. We also appreciate the moral support and invaluable comments from the students and lecturers in Mathematical Finance at Strathmore University.

\section{References}

[1] Markowitz, H. (1952) Portfolio Selection. The Journal of Finance, 7, 77-91.

[2] Markowitz, H. (2010) Portfolio Theory as I Still See It. Annual Review of Financial Economics, 2, 1-23. https://doi.org/10.1146/annurev-financial-011110-134602

[3] Gilli, M. and Schumann, E. (2009) An Empirical Analysis of Alternative Portfolio Selection Criteria. Swiss Finance Institute Research Paper, No. 09-06.

https://doi.org/10.2139/ssrn.1365167

[4] Chen, L., Peng, Z., Zhang, B. and Rosyida, I. (2016) Diversified Models for Portfolio Selection Based on Uncertain Semivariance. International Journal of Systems Science, 48, 637-648. https://doi.org/10.1080/00207721.2016.1206985

[5] Zhang, B., Peng, J. and Li, S. (2015) Uncertain Programming Models for Portfolio Selection with Uncertain Returns. International Journal of Systems Science, 46, 2510-2519. https://doi.org/10.1080/00207721.2013.871366

[6] Dueck, G. and Scheuer, T. (1990) Threshold Accepting: A General Purpose Optimization Algorithm Appearing Superior to Simulated Annealing. Journal of Computational Physics, 90, 161-175. https://doi.org/10.1016/0021-9991(90)90201-B

[7] Chang, T.J., Yang, S.C. and Chang, K.J. (2009) Portfolio Optimization Problems in Different Risk Measures Using Genetic Algorithm. Expert Systems with Applications, 36, 10529-10537. https://doi.org/10.1016/j.eswa.2009.02.062

[8] Gilli, M. (2004) An Introduction to Optimization Heuristics. Department of Public and Business Administration, Seminar University of Cyprus, Nicosia, Republic of Cyprus.

[9] Gilli, M. and Schumann, E (2012) Heuristic Optimisation in Financial Modelling. Annals of Operations Research, 193, 129-158. https://doi.org/10.1007/s10479-011-0862-y

[10] Consigli, G., Kuhn, D. and Brandimarte, P. (2017) Heuristics for Portfolio Selection. In: Optimal Financial Decision Making under Uncertainty. International Series in Operations Research \& Management Science, 245, 255-290.

[11] Nyokangi, C.O. (2016) Relative Performance of the Single Index versus Mean Variance Optimization in Equity Portfolio Construction in Kenya. Masters Dissertation, Strathmore University, Nairobi.

https://su-plus.strathmore.edu/handle/11071/4770 
[12] Fastrich, B. and Winker, P. (2012) Robust Portfolio Optimization with a Hybrid Heuristic Algorithm. Computational Management Science, 9, 63-88. https://doi.org/10.1007/s10287-010-0127-2

[13] Idzorek, T.M. (2004) A Step-by-Step Guide to the Black-Litterman Model. Incorporating User-Specified Confidence Intervals. Zephyr Associates, Inc.

[14] Gilli, M., Këllezi, E. and Hysi, H. (2006) A Data-Driven Optimization Heuristic for Downside Risk Minimization. The Journal of Risk, 8, 1-19. https://doi.org/10.21314/JOR.2006.129

[15] Menge, R.N., et al. (2014) Effect of Elections on Stock Market Returns at the Nairobi Securities Exchange. Prime Journal of Social Science, 3, 763-768.

[16] Rollinger, T. and Hoffman, S. (2013) Sortino Ratio: A Better Measure of Risk. Futures Magazine, February 2013, 40-42.

[17] Biglova, A., Ortobelli, S., Rachev, S. and Stoyanov, S. (2004) Different Approaches to Risk Estimation in Portfolio Theory. The Journal of Portfolio Management, 31, 103-112. https://doi.org/10.3905/jpm.2004.443328

[18] Kolm, P.N., Tütüncü, R. and Fabozzi, F.J. (2014) 60 Years of Portfolio Optimization: Practical Challenges and Current Trends. European Journal of Operational Research, 234, 356-371. https://doi.org/10.1016/j.ejor.2013.10.060

[19] Fabozzi, F.J., Gupta, F. and Markowitz, H.M. (2002) The Legacy of Modern Portfolio Theory. The Journal of Investing, 11, 7-22. https://doi.org/10.3905/joi.2002.319510

[20] Gilli, M. and Schumann, E. (2011) Optimal Enough? Journal of Heuristics, 17, 373-387. https://doi.org/10.1007/s10732-010-9138-y

[21] NSE (2016) Listed Companies. https://www.nse.co.ke/listed-companies/list.html

[22] Kabiru, J.N., Ochieng, D.E. and Kinyua, H.W. (2015) The Effect of General Elections on Stock Returns at the Nairobi Securities Exchange. European Scientific Journal, 11, 435-460.

[23] Durnev, A. (2010) The Real Effects of Political Uncertainty: Elections and Investment Sensitivity to Stock Prices.

[24] Dou, P.Y., Gallagher, D.R., Schneider, D. and Walter, T.S. (2014) Cross-Region and Cross-Sector Asset Allocation with Regimes. Accounting \& Finance, 54, 809-846. https://doi.org/10.1111/acfi.12017 


\section{Appendix}

\section{Codes of Stocks Used}

Table 11. Kenyan stocks considered in the optimization models. Source of Codes: NSE (2016) [24].

\begin{tabular}{|c|c|c|}
\hline Code & Company & Company Sector \\
\hline ARM & ARM Cement Ltd & Construction and Allied \\
\hline BAMB & Bamburi Cement Ltd & Construction and Allied \\
\hline $\mathrm{BBK}$ & Barclays Bank of Kenya Ltd & Banking \\
\hline BERG & Crown Paints Kenya Ltd & Construction and Allied \\
\hline $\mathrm{BOC}$ & B.O.C Kenya Ltd & Manufacturing and Allied \\
\hline C\&G & Car and General (K) Ltd & Automobiles and Accessories \\
\hline CABL & E.A.Cables Ltd & Construction and Allied \\
\hline CFC & CFC Stanbic of Kenya Holdings Ltd & Banking \\
\hline DTK & Diamond Trust Bank Kenya Ltd & Banking \\
\hline EABL & East African Breweries Ltd & Manufacturing and Allied \\
\hline FIRE & Sameer Africa Ltd & Automobiles and Accessories \\
\hline HFCK & Housing Finance Group Ltd & Banking \\
\hline ICDC & Centum Investment Co Ltd & Investment \\
\hline JUB & Jubilee Holdings Ltd & Insurance \\
\hline $\mathrm{KCB}$ & KCB Group Ltd & Banking \\
\hline KENO & KenolKobil Ltd & Energy and Petroleum \\
\hline KQ & Kenya Airways Ltd & Commercial and Services \\
\hline KUKZ & Kakuzi Ltd & Agricultural \\
\hline NBK & National Bank of Kenya Ltd & Banking \\
\hline $\mathrm{NIC}$ & NIC Bank Ltd & Banking \\
\hline NMG & Nation Media Group Ltd & Commercial and Services \\
\hline $\mathrm{OCH}$ & Olympia Capital Holdings Ltd & Investment \\
\hline SASN & Sasini Ltd & Agricultural \\
\hline SCBK & Standard Chartered Bank Kenya Ltd & Banking \\
\hline SGL & Standard Group Ltd & Commercial and Services \\
\hline SNLM & Pan Africa Insurance Holdings Ltd & Insurance \\
\hline TOTL & Total Kenya Ltd & Energy and Petroleum \\
\hline UNGA & Unga Group Ltd & Manufacturing and Allied \\
\hline XPRS & Express Kenya Ltd & Commercial and Services \\
\hline
\end{tabular}

